\title{
Retaining Sales Associates in the Small Business Industry
}

\author{
Benjamin 0. Chukwu \\ Walden University, Minneapolis, Minnesota, USA \\ Email: benjamin.chukwu9@outlook.com
}

How to cite this paper: Chukwu, B. O. (2021). Retaining Sales Associates in the Small Business Industry. Open Journal of Business and Management, 9, 1858-1889. https://doi.org/10.4236/ojbm.2021.94101

Received: February 15, 2021

Accepted: July 20, 2021

Published: July 23, 2021

Copyright $\odot 2021$ by author(s) and Scientific Research Publishing Inc. This work is licensed under the Creative Commons Attribution International License (CC BY 4.0).

http://creativecommons.org/licenses/by/4.0/ (c) (i) Open Access

\begin{abstract}
The purpose of this multiple case study was to explore the managerial strategies that small businesses owners used to motivate and retain sales associates to increase profits. The study population included 4 small business owners in Texas who successfully implemented employee motivation and retention strategies. Data were collected from semistructured interviews, artifacts that included company websites and social media pages. The transformational leadership theory guided the study. Data were analyzed using Yin's 5 steps of data analysis, including compiling data, disassembling data, reassembling data, interpreting data, and drawing conclusions. Three themes emerged from the data analysis: provide financial incentives, increase job satisfaction, and enhance job training. The findings showed that small business owners use the strategies to motivate and retain sales associates to increase business profits. This study's results could contribute to positive social change by helping other small business owners implement motivation and retention strategies, which might enhance business sustainability. Business sustainability supports both local and state economies and fosters an optimum distribution of resources in the community.
\end{abstract}

\section{Keywords}

Employee Motivation, Employee Retention, Employee Turnover, Job Performance, Job Satisfaction

\section{Introduction and Background}

Business owners and managers in the small business sector may need to understand leadership strategies' significance to improve business productivity and profitability. This study is organized into three sections. The first section includes the introduction and background, the research question, assumption, limitation, 
and delimitations. In addition, the first section includes the significance of the study and a review of the academic literature. The second section comprises the research method and design, population, sampling, and data section. In addition, the second section includes reliability and validity. The third section includes the finding, primary contributions, application to professional practice, recommendations for further action, and conclusion. The small business sector in the United States contributes to $99.9 \%$ of the economy (Small Business Association $[\mathrm{SBA}], 2016)$. With these statistical findings from the SBA, the small business sectors play a significant role in enhancing the United States' national economy.

Conversely, lack of motivation can negatively impact the business. In this study, I explored the strategies small business owners use to motivate and retain sales associates to increase business profits. Motivating and retaining employees are critical to keeping and improving business productivity, which directly benefits business profitability (Bucata \& Rizescu, 2017). Motivation can also help small businesses to remain operable, thereby strengthening the economy. The purpose of this research was to explore the strategies small business owners used to motivate and retain their sales associates.

Motivating employees may enable small business owners to remain competitive. Small business has played a significant role in job creation and economic growth in the United States (U.S. Census Bureau, 2016). Successful small businesses are vital to the U.S. economy and small businesses employ $64 \%$ of the private workforce and provide more than $40 \%$ of private sales (SBA, 2016). Companies can gain a competitive advantage when employees are motivated, which positively influences business profitability (Kumar \& Pansari, 2016). This study's results might make an essential contribution to the existing body of literature by providing supportive data on employee motivation.

\subsection{Purpose Statement}

Business owners experience low employee productivity and lost profits when they cannot motivate and retain employees (McManus \& Mosca, 2015). An organization may negatively impact productivity and profitability when employees lack motivation and job satisfaction (Baskar \& Rajkumar, 2015). The Bureau of Labor Statistics (2015) indicated that the annual employee small business voluntary turnover rate increased from $26.8 \%$ in 2010 to $33.5 \%$ in 2014, with a national average of $22 \%$. The general business problem is that if business owners do not motivate employees to reduce turnover, they may experience lost profits. The specific business problem is that some small business owners lack strategies to motivate and retain sales associates to increase profits.

\subsection{Research Question}

The central research question guiding this study was: What strategies do small business owners use to motivate and retain sales associates to increase profits? 
Data derived from semistructured interview questions, Company websites, and documents.

\subsection{Assumptions, Limitations, Delimitations}

A researcher's assumptions are convictions that are factual and authentic (Marshall \& Rossman, 2016). First, I assumed that every participant that I interviewed provided an honest response to each question. Second, I assumed that participants provided detailed information to enhance the study at the interview time.

Limitations are possible weaknesses beyond the researcher's control in a research procedure (Matza et al., 2015). The use of a case study involves interviewing a small population knowledgeable about a phenomenon; the findings generated from this confined group may not produce generalizations about an entire industry or geographic area.

Delimitations consist of a study's boundaries within the researcher's control (Thomas, Silverman, \& Nelson, 2015). The geographical parameter of the study was the State of Texas. Participants were four business leaders who have used motivational strategies to retain employees successfully.

\subsection{Significance of the Study}

This study may contribute to business practice by identifying transformational leadership strategies that business leaders have used to aid employee retention and build business profitability. Improved employee retention may strengthen consistency in business practices, enhancing business-customer relations and, thus, customer loyalty. Focusing on motivational factors to enhance retention and profitability may increase business stability and longevity, supporting business growth.

This study may contribute to social change by creating a work environment where individuals want to work, thus stabilizing family incomes and economic independence. Therefore, financial independence stimulates the exchange of goods and services, promotes business development, fuels local economies, and enhances employment options for local citizens. The theory guiding the study was transformational leadership by Burns (1978). Transformational leadership is an approach business leader use to raise inspiration and business performance and profitability through guidance and interaction between leaders and subordinates to enhance employee productivity (Manning \& Kurtis, 2012).

\section{A Review of the Academic Literature}

\subsection{Transformational Leadership}

I selected transformational leadership theory because transformational leadership offers a robust set of leadership values and idealized influence and effective, inspirational motivation, intellectual stimulation, and individualized considera- 
tion. The transformational leadership theory was introduced by Downtown in 1973 and developed by Burns in 1978. Transformational leaders build relationships to influence and inspire their subordinates to support organizational goals (Northouse, 2016; Zhang et al., 2015). Some researchers have referred to the transformational leader as an innovative leader who makes a difference in the economy, public, private, and education (Northouse, 2016; Zhang et al., 2015). Thus, the transformational leader provides insights in guiding company stakeholders successfully through a process of change, and change has generated many opportunities in business (Malik, Saleem, \& Naeem, 2016). For instance, the co-founder of Apple Computer, the late Steve Jobs, was an excellent example of a transformational leader who transformed Apple Computer and introduced a new iPhone that millions of people worldwide use. Steve Jobs, remembered as innovative, dynamic, charismatic, motivational, and inspirational, was also a transformational leader. Organizations are searching for leaders who are enlightened, motivational, and can bring change to an organization.

The organization's success lies in the leader's ability to effectively manage stress and address followers' various needs (Malik et al., 2016). Malik et al. argued that every organization needs a leader who strives for the organizational mission, vision, goals, and objectives effectively and empowers, motivates, and inspires followers. Influential leaders build long-lasting relationships with all stakeholders. Transformational leaders treat their subordinates well and fulfill their employees' needs (Bamdale, Girei, \& Barwa, 2017). Further, transformational leadership helps organizations achieve the objectives more efficiently by linking job performance to valued rewards and ensuring that employees have the resources needed to get the job done.

Additionally, transformational leaders motivate subordinates and appeal to their ideas and moral values by creating and representing an inspiring future vision. Abdullah and Varatharajoo (2017) indicated that transformational leaders motivate, inspire, and encourage their subordinates to perform beyond what the employees thought possible to attain organizational goals. Alatawi (2017) listed Burns' four transformational leadership components as 1) intellectual stimulation, 2) individualized consideration, 3) inspirational motivation, and 4) idealized influence that small business owners, managers, and organization leaders can use to motivate their subordinates.

\subsection{Employee Motivation}

Establishing a mutually beneficial relationship between the leader and employee is crucial to identifying strategies to motivate employees. Organizations need to introduce new employees' motivational strategies to enhance organizational profitability (Kushwaha \& Lodhwal, 2016). Motivation is a process that rejuvenates employee behavior toward achieving organizational goals. The organization leader uses motivational techniques within a productive work environment to enhance and improve employee productivity. 
Organizational leaders face numerous challenges due to a lack of adequate leadership skills related to bolstering employee. The lack of leadership skills leads to decreased productivity. Organizational leaders play a significant role in influencing their employees positively to achieve the organization's objectives. Job design is a factor that can increase workflows (Porter, Rieseny \& Fields, 2016). When employees find meaning in the jobs, they are more likely to devote additional effort to an organization. Porter et al. indicated that a well-designed job leads to innovation and internal employee motivation. The ability to motivate employees should be one of the most critical factors organizational managers should employ or integrate to foster organizational growth and progress (Kubica \& Szarucki, 2016).

The notion of inspiration is a technique to impact employees' behavior in the work process by fostering an autonomous workplace that reinforces idealism, thus enhancing the environment to promote free-thinking and innovation. Gunasekara (2018) suggested that employee motivation is one of the most critical factors for organization success. Promoting a spirit of innovation, through motivational techniques, means an organization inspires their employees with some rewards, bonus, and other incentives to enhance organizational goals. Kuznetsova et al. (2017) noted that the key element in an organization is the development of an efficient motivation strategy. A motivated employee is an organization's most significant asset capable of creating new value to improve its objectives and improve labor efficiency.

The development of relationships within an organization fuels motivation. A high-quality relationship between organizational leadership and employees plays a significant role in employee motivation (Malik, Wan, Ahmad, Naseem, \& Rehman, 2015). Malik et al. argued that leaders have considerable influence on the motivation of the subordinates. Complex working environments are a source of employee stress; and stress is controllable through motivation strategies. Effective leaders should motivate their employees to achieve organizational goals and objectives (Çakir \& Kozak, 2017). Thus, motivation is one of the critical determinants of employee performance. Çakir and Kozak suggested that highly motivated employees exhibit higher levels of organizational commitment. In contrast, dissatisfied employees have an increased tendency to engage in counterproductive behaviors, such as employee disengagement and employee turnover. Delaney and Royal (2017) emphasized that employee motivation as a core component of engagement may lead to employee retention. Also, motivation helps employees to be proactive in moving organizational strategies forward for better profitability. Intrinsically motivated employees are more innovative, thus, solve problems more efficiently and effectively.

Job satisfaction enhances business performance and profitability. Motivation, either intrinsically or extrinsically, contributes to employee job satisfaction, improving productivity and profitability (Kuranchie-Mensah \& Amponsah-Tawiah, 2016). Organizations use the motivation factor as a change management strategy 
to enhance the work environment (Kuranchie-Mensah \& Amponsah-Tawiah, 2016). Motivating employees is an excellent approach for organizational development and improvement (Kuranchie-Mensah \& Amponsah-Tawiah, 2016). Similarly, organizational leaders who educate employees on new technologies and leadership skills will improve the organization. Kang, Gun, and Lee (2016) added that some organizational leaders used various compensation strategies to boost employee morale to provide a reward in response to employee performance. Change management creates varied outcomes, while increased individual motivation levels positively enhance personal and organizational performance (Kuranchie-Mensah \& Amponsah-Tawiah, 2016). Also, rewarding employees prevented talented employees from voluntarily leaving the organization to promote stability, continuity, and longevity.

Leaders play a critical role in leading their subordinates to fulfill organizational objectives. Leadership is a process that motivates or influences others to achieve positive changes in an organization, which subsequently helps increase the productivity and profitability of the organization (Fiaz, Su, Ikram, \& Saqib, 2017). Organizational leaders must adopt an effective leadership style to help stimulate employee motivation.

Motivation as a strategy is an effective way to enhance change management initiatives in an organization. Motivational techniques and human resources management are essential assets to improve organizational profitability. Reward programs, such as job security, job satisfaction, and manager's ability and attitude towards employees, play a significant role in employee motivation (Klopotan, Mjeda, \& Kurečić, 2018). Zareen, Razzaq, and Mujtaba (2015) added that employee motivation is essential for accomplishing organizational goals. Organizational leaders should improve employee motivation for the good of an organization. Furthermore, the primary source of competitive advantage for any organization is effective leadership (Zareen et al., 2015). Thus, effective leadership plays a vital role in the growth and better profitability of any organization.

\subsection{Employee Retention and Turnover}

Employee retention issues are a primary concern for business owners in the U.S. Organizations are affected by increased employee turnover (Dhanpat, Madou, Lugisani, Mabojane, \& Phiri, 2018). As a result, business owners rigorously search for ways to improve employee motivation and job satisfaction to improve employee retention. Organizational leaders struggle with understanding what promotes employee retention, as various factors influence employees to remain with one company. Thus, employee retention, motivation, and job satisfaction should be a priority; creating effective retention strategies to decrease turnover is of paramount importance. Dhanpat et al. suggested retention relies upon compensation, career advancement, job satisfaction, training, and development, among other strategies. Employee retention creates challenges for many organizations (Anitha \& Begum, 2016). 
Employees are the most valuable assets of every organization, and organizational leaders cannot afford to lose vital talented employees. Therefore, employee turnover creates undue stress on business leaders and employees alike if qualified employees voluntarily leave. Many organizational leaders work to retain and motivate their employees by implementing effective retention strategies, including various loyalty-building incentives (Anitha \& Begum, 2016). Other factors organizations should employ include demonstrated commitment to employees and a healthy organizational culture. Motlou, Singh, and Karodia (2016) underscored the impact of job satisfaction and employee retention and highlighted that job satisfaction is crucial for employee retention.

Employee retention is the primary focus of many organizations. Organizational leaders must create a healthy environment and more opportunities for their employees. Policies can facilitate employee's job satisfaction by providing standards and pathways for resolving workplace conflicts (Motlou et al., 2016). In conclusion, when employees lack satisfaction with their jobs, the situation might force them to look for jobs where some well-established organizational policies protect employees' jobs and encourage retention. Also, a lack of adequate development strategies, motivation, and promotion opportunities, encourage employees to leave the organization. Thus, job satisfaction affects employee retention.

Recruitment strategies may provide insights into possible retention potential. Sutanto and Kurniawan (2016) examined the impact of recruitment, employee retention, and labor relations on employee performance within the Batik industry in Solo City, in Indonesia. The focus of the exploration was employee retention and profitability. Retention of employees positively influences organizational profitability (Sutanto \& Kurniawan, 2016). A good recruitment program positively affects employee commitment, productivity, work quality, higher employee retention, and profitability.

Employee retention requires strategic measures to encourage employees to extend their commitment to a business, promoting organizational stability. Retention is achievable through rewards, incentives, bonuses, and other employee benefits. Bindu (2017) suggested that employee retention and commitment had become an important strategy adopted by many organizations to increase work performance. For instance, employee job satisfaction and motivation are essential tools to enhance employee retention. When an employee is satisfied with a tangible, such as pay, this may result in increased productivity and profitability; thus, increasing the potential for organizational goal achievement.

Business owners have many strategies they can apply to enhance employee retention. Voluntary employee turnover is a process that results from business owners' or organizational leaders' inability to ensure employee retention. Employees pay satisfaction, motivation, and a spirit of creativity and innovation within the organization are examples of employee retention factors. Some business owners embrace common ethical leadership frameworks creating difficul- 
ties in motivating and retaining employees, resulting in high employee turnover (Nica, 2016). Some employees may leave their job because due to dissatisfaction. Therefore, any organization leader who wants to retain their most talented employees should consider paying satisfaction an essential tool to improve job performance and productivity. Nica further highlighted that organizational leaders should apply effective leadership strategies to enhance employee well-being to reduce employee turnover. Employees' commitment is paramount to the survival of a business, and any organization that lacks knowledge and strategy regarding how to invest in employees may fail or experience reduced profits (Azeez, Jayeoba, \& Adeoye, 2016). In addition, organizational commitment to employees may reduce employee turnover.

Employee commitment or satisfaction is crucial for the efficiency, profitability, and growth of an organization. Conversely, employee dissatisfaction may result in employee turnover. Organizational commitment, such as motivation, incentives, and job satisfaction, helps reduce turnover. Azeez et al. (2016) underscored that employee job satisfaction leads to higher organizational commitment, and commitment leads to low employee intention to leave (turnover). Generally, commitment leads to organizational growth and increased business profits. Employee turnover is by employees who are not satisfied in their current jobs because of a lack of organizational commitment (Devi \& Krishna, 2016). An organization might consider compensating their employee through different reward programs, such as bonuses, training and development, and job satisfaction, and so forth. Devi and Krishna argued that many organizations face more significant challenges on how to reduce employee turnover. Also, they indicated that human resource (HR) management practices have a considerable influence on minimizing employee turnover. Further, the relationship between HR practices and employee turnover in the organization is evident, and consequently, ineffective HR practices could lead to increased employee turnover.

\subsection{Motivating Employees of Small Business Owners}

Small businesses are essential in a global economy. Employees of small businesses play a crucial role in delivering innovative quality products and services, which results in customer satisfaction (Vlacsekova \& Mura, 2017). Small business owners should use effective strategies to enhance employee motivation. Group motivation incentives can apply when collaboration is a requisite of performance and workplace harmony. Business owners might consider increasing employee involvement in decision-making processes and career advancement opportunities, rewards, or bonuses (Vlacsekova \& Mura, 2017). Employees should gain encouragement to be creative and innovative. They should receive periodic positive and corrective feedback and recognize accomplishments such as a finished project, reaching sales goals, or providing excellent customer service. Viacsekova and Mura concluded that small businesses should apply Maslow and Herzberg's motivational factors, which implied that many factors motivate em- 
ployees. Business owners have the responsibility to implement an effective strategy for employee motivation.

Thus, effective employee's motivation will lead to adequate job performance and customer satisfaction. Rozman, Treven, and Čančer (2017) suggested that small business owners should design jobs or create a good workplace environment to reduce employee stress and implement motivational strategies that would lead to employee satisfaction and improved profitability. Furthermore, small business owners operate in a competitive climate globally (Rozman et al., 2017). Thus, employee job satisfaction is of paramount importance for business performance and efficiency. Poor management practices in the diverse workplace can negatively influence employee job performance (Rozman et al., 2017). For example, when employees experience stereotypes or prejudices, this action reduces employee morale and performance.

For effective and successful business improvement, Rozman et al. (2017) suggested that business owners should adopt diversity in the workplace and motivate their employees to boost organizational performance. Kubica and Szarucki (2016) highlighted the importance of motivating employees as a critical factor for business success, which ideally involves the integrated motivational strategies for work performance. For example, financial and non-financial incentives are essential motivators. Also, education, training, and career development are other factors that would improve employee motivation. Business owners or management should emphasize using effective strategies to promote and enhance employee motivation to increase business profitability and growth.

\subsection{Leadership, Employee Communication, and Motivation Strategies}

Employees are one of the most critical stakeholders and significant to the organizations' effectiveness and success. Management must map out practical approaches such as employee organizational relationship (EOR) strategies. The values of internal communications have improved and enhanced relationships with employee engagement and motivation (Kang \& Sung, 2017). Excellent employee communications could produce quality employee relationships and target employee behaviors to the organizational vision. For instance, employees who receive positive performance feedback tend to exhibit motivation and maintain trusting relationships with the organization (Kang \& Sung, 2017). Additionally, certain internal organizational practices, such as regular and transparent communications with employees, associate with good employee-corporate relationships. Similarly, the effectiveness of internal communication is a leading indicator of small or medium-sized organizational success.

Communication satisfaction is an essential element in a well-functioning business. When employees come from diverse cultures, understanding cultural diversity might pose challenges in developing a productive business relationship (Jalalkamali, Ali, Hyun, \& Nikbin, 2016). Communication among staff and 
management plays a crucial role in job satisfaction (Jalalkamali et al., 2016). Communication is one of the most critical approaches by management (Bucata \& Rizescu, 2017). Being a corporate leader does not only mean to rein in business, but more importantly, to coordinate employees, leadership skills, and communicate more effectively help facilitate progress toward job performance (Bucata \& Rizescu, 2017). Employees' effective communication and motivation may help the organization perform effectively in achieving beneficial results (Bucata \& Rizescu, 2017). Also, to enhance team dynamics, managers should bridge gaps between team members of the organization through purposeful and active communication. Through better communication, organizational activities may generate success, which could also improve job satisfaction and performance. Therefore, effective communication should facilitate the relationship between leaders and employees to establish a better workplace environment. Manager communication with the employees should be a top priority for managers in achieving company goals and objectives. Employee participation is crucial to engaging in the organizational decision-making process, communication, and teamwork to impact job satisfaction (Avani \& Gulzar, 2016). Employee participation and open communication are essential to provide the platform to share their ideas in a team setting, with collective experience and knowledge, which may motivate employees. Lee, Lee, and Sohn (2017) pointed out that organizational communication generally provides employees with accurate corporate information and opportunities to affect the administrative decision-making process. In these cases, organizational communication reduces the uncertainty related to employee tasks. Effective communication can lead to positive employee-level outcomes.

Communication with managers and other workers enables employees to affect the organizational decision-making process, cooperate, and coordinate work projects positively and effectively. The way a leader communicates with employees affects their motivation toward the work commitment (Gutierrez-Wirsching, Mayfield, Mayfield, \& Wang, 2015). Thus, communication is a vital component of good leadership. Influential leaders know that only by opening to people and sharing valuable information they can obtain input from employees. However, effective communication and motivation strategies improve employee performance (Gutierrez-Wirsching et al., 2015). Job satisfaction, inspirational leadership, employee motivation, and positive communication with employees, was beneficial to organizational success (Justin, Kaitlynn, Bharat, \& Jitendra, 2017). Additionally, a company's leaders' ability to provide regular and helpful feedback and positive communication to employees is the basis for effective management (Justin et al., 2017). A leader's feedback conveys in an impolite way to subordinates, might lower employees' morale, and, consequently, may result in employees searching for new jobs.

Communication and motivation through reward and recognition, training, and development are crucial elements in executing leaders' strategies to reach goals and 
objectives. Employees have been the primary driver and resource that benefits organizations by contributing to decision-making strategy formulation, translating, and communicating the strategy into operational practices (Thanyawatpornkul, Siengthai, \& Johri, 2016). For effective workflows and efficiency, leaders and managers must share the plans for simple concepts or ideas to employees and relate them to their various daily work activities. Leaders and managers must demonstrate the leadership philosophy and act accordingly for the progress of the organizations. For example, during strategy execution, communication is a continuous process, achievable through regular meetings, posters, emails, newsletters, Intranet, broadcasting, and special events.

Effective two-way communication is critical in translating strategy into actions, from corporate to business units to frontline employees. Effective and efficient communication creates a vibrant and healthy environment in organizations. Well-informed communication might lead to new knowledge and ensure a better understanding of leadership strategies and direction. However, a company must provide an environment where everyone is free to communicate openly, without fear, and support an organization's strategy in obtaining favorable outcomes. Additionally, transparent, and effective communication rules are of importance to complete tasks.

\section{Research Methodology}

A multiple case study was more appropriate for this study than a single case study design because using a single case study would produce some insight. At the same time, it might create biases that may result in a deficiency regarding reliability, dependability, validity, credibility, and confirmability. Yin (2016) argued that two or more evidence examples are more representative than a single case study. Each organization may operate differently and may offer unique strategies to establish a competitive edge. A multiple case study may give researchers an opportunity and flexibility to gather various information from different participants about the strategies small business owners use to motivate and retain sales associates to increase profits. The multiple case study design allows researchers to collect data from various sources to gain access to the evidence and understand the phenomenon under investigation (Yin, 2016). Using a case study design allowed me to use interviews, documentation, and physical artifacts to gain narrative explanations on small business owners' decisions on strategies they use to motivate and retain their sales employees to increase profits.

\subsection{Population and Sampling}

This study's population consisted of leaders of four small businesses located in Texas who have applied various strategic approaches in employee motivation and retention. A researcher must ensure that all participants satisfy specific eligibility criteria and possess the ability to answer the researcher's question when applying purposive sampling (Galvin, 2015). I purposefully selected participants 
who were 1) small business owners, 2) had successfully motivated and retained employees, and 3) agreed to participate in this study. A reasonable sample size is 10 to 12 participants (Apostolopoulos \& Liargovas, 2016). Saturation was reached with four participants. Sample size should allow the researcher the best opportunity to reach data saturation (Fusch \& Ness, 2015). Galvin (2015) stated that a critical element in upholding validity within research is for the researcher to achieve data saturation. Fusch and Ness (2015) indicated researchers reach saturation when the addition of new data provides no additional information. I did select participants that met the eligibility requirements to participate in this study. The researcher should select participants who know and experience the phenomenon and provide general and detailed data (Apostolopoulos \& Liargovas, 2016). Each participant had a thorough knowledge about successful strategies to motivate and retain employees to increase profits. The successful strategies included financial incentives, increased job satisfaction and they provided enhance job training.

Additionally, I used purposeful criterion sampling for this study because it aligned with my intent to conduct a qualitative multiple case study. A researcher's goal of using purposive sampling is to have participants yield the most critical, relevant, and plentiful data on the study's topic (Yin, 2016). Marshall and Rossman (2016) found that purposeful participant selection can assist the researcher in addressing the research question. If the original candidate pool had drained and I did not reach saturation, I would have applied snowball sampling to access other potential participants who met the criteria to exhaust the interview process (Fusch \& Ness, 2015).

\subsection{Data Collection Instruments}

As the researcher, I was the primary data collection instrument in this study. Additional instruments included semistructured interviews questions, pencil and paper for recording nuances, a tape recorder, and interview protocol. The use of an interview protocol guides the interview process ensuring all questions and asking questions, remains consistent to enhance the reliability of the research. I conducted semistructured interviews with owners of four small businesses in Texas State. Yoke-Mui, Ahmad, and Nabavi (2016) stated that semistructured interviews allow for a thorough investigation of the business problem. Khan (2016) argued that the qualitative semistructured interview technique is popular among qualitative researchers.

Furthermore, open-ended probing questions help obtain detailed responses from the interviewees (Ozer \& Douglas, 2016). The data collection process involves a series of activities, including gaining permission, conducting sampling strategies, engaging in interviews, recording, and sorting data, and resolving ethical issues that may arise (Yin, 2016). A researcher provides the data interpretations to the participants to member check each contribution to ensure information collected is accurate, and if not, the researcher will alter the data to re- 
flect the intentions of the participant; this process enhances the validity of the research process (Moreland \& Apker, 2015).

\subsection{Data Organization Techniques}

Morrison, Clement, Nestel, and Brown (2016) suggested that qualitative researchers frequently use primary data collection methods such as semistructured face-to-face interviews, telephone interviews, questionnaires, and audio-recording. The advantage of using face-to-face interviews in a case study is that face-to-face interviewing is more direct and straightforward (Gadalla, Abosag, \& Keeling, 2016). The researcher gains a valuable understanding of the problem and develops rapport, trust, and understanding between the researcher and interviewees.

Conversely, a disadvantage of the face-to-face interview is potential bias if the researcher inadvertently influences the results by infusing incorrect inferences (Yin, 2016). To avoid or reduce the data collection's personal bias, I used member checking to avoid misinterpretation of the interview transcripts. Member checking is a method to share a participant's interview data with the participant to establish the interview data's accuracy (David, Hitchcock, Ragan, Brooks, \& Starkey, 2016). Another disadvantage of using face-to-face interviews in data collection is that the environment or the interview place might be a source of distraction if not controlled well by the researcher (Gadalla et al., 2016). I applied member checking techniques to mitigate bias, increase trustworthiness, and follow the necessary steps as planned. Klenke (2016) highlighted that interviews are the most popular method of collecting data in qualitative research. I used an interview protocol was to ensure each interview conforms to the requirements for a case study. The interview protocol helps increase the reliability of the research process. Researchers use in-depth interviews to collect data that are impossible to gather from common observation (Cairney \& St. Denny, 2015; Kihn \& Ihantola, 2015).

A researcher can use a telephone conference for interviewing the participant where face-to-face meetings are not possible. During the interview process, the interview with each participant took approximately about 30 minutes. The use of an interview protocol, a step-by-step approach to guide the interview process, will ensure the researcher stays within parameters to ask questions and helps the researcher treat each interview in the same manner (Yin, 2016). The interview protocol contains the interview questions directing the interviewer through the interview process (Chen \& Mykletun, 2015). I used an interview protocol to ensure consistency in the interview procedure. The use of a recording device helped record interviews, and wearing a watch was to ensure the interviews stayed within the planned time limits. I used a pencil and paper approach to take notes during the interview proceeding as a suitable tool to capture subtle nuances. My strategy for data collection was to transcribe the recorded data into a Microsoft Word and Excel spreadsheet. 
I asked open-ended and probing questions to gain a comprehension perception of the business problem. As a result, I gained a deeper understanding of the strategies small business owners use to motivate and retain employees to increase business profits. I encouraged participants to respond to the interview questions honestly and openly. I used an audio-recorder with the participant's permission to record the interview sessions and supplement with other company archival documents, such as sales reports.

\subsection{Data Organization Techniques}

I used a notebook to write down the date, time, and other vital information about the interview. Reflective journaling is essential to the data organization process and contains field data related to the information collected. Researchers must organize, format, and arrange all interview data properly secured to maintain the confidentiality of every participant's information (Brennan \& Bakken, 2015; Yin, 2016). Each research participant was assigned a unique pseudonym and labeling format for distinguishing each participant's contribution and protecting the interview process's integrity. I labeled any electronic files of the interview data with the participant's pseudonym, P1, P2. Marshall and Rossman (2016) recommended labeling and categorizing data for consistency to protect the participants' confidentiality.

\subsection{Data Analysis}

Gill et al. (2016) argued data analysis is a process for making sense of data. The use of methodological triangulation ensures the study includes an exploration using multiple lenses, such as interview data, documentation, and physical artifacts (Yin, 2016). Before analyzing the collected data, I organized the information from the various sources, interviews, documentation, and artifacts. I also reviewed the related literature that supports and refutes research concepts, which draw on the conceptual framework to ground the study within a research context.

I engaged in the data analysis process by coding the collected data, highlighting key ideas and terms, and keeping a count of the data frequency. I opted to use pencil and paper analysis instead of software as both approaches provides the same outcomes. Still, I was more interested in coding and clustering as a 'hands-on' process, as opposed to a software tabulation of frequencies. Data analysis involves two distinct processes, data reduction and data interpretation (Marshall \& Rossman, 2016). The purpose of data analysis is to make meaning out of raw data. I manually transcribe the collected data, organize the data through coding and clustering, and develop themes from the patterns evolving in the data. The process of thematic analysis involves capturing repeated ideas and terms. The process eventually and ideally leads to a clear summary of the findings applicable to the research process's goals and intentions. 


\subsection{Reliability and Validity}

In qualitative research, reliability and validity are crucial to ensure the trustworthiness of an investigation. Reliability indicates the consistency of the researcher's approach (Marshall \& Rossman, 2016). Researchers must pursue trustworthiness and dependability by truthfully specifying the data gathering and data analysis processes and results (Webster, Brown, Mathew-Maich, \& Patterson, 2016). I used an interview protocol because a researcher can use the interview protocol as a guide for the interview to mitigate misunderstandings and prejudices and ensure the researcher reliably employed the same data collecting procedure and analysis. The qualitative focus is upon the credibility of evidence collected and a conclusion reached (Parker \& Northcott, 2016).

Dependability in qualitative study ensures that audiences can rely on the research discoveries and follow the researchers' specific research techniques in conducting the research (Marshall \& Rossman, 2016). To establish dependability in a case study, researchers apply consistent interview and analysis strategies. A part of this process is using an interview protocol to ensure alignment with the central research question and applying a consistent approach to analysis through appropriate coding, clustering, and theme development, consistent with a case study approach. The application of triangulation of multiple sources of data can enhance the study's reliability and enable the researcher to explore a business problem through multiple lenses. The researcher can also establish dependability by utilizing a triangulation technique, such as reviewing existing company documentation or website information (Fusch, Fusch, \& Ness, 2018). Dependability develops through repetitively conducting interviews, gaining a breadth of responses, and identifying both common and less common responses to explain business strategies. Dependability develops through consistency, diligence, and confirmation that all information collected is accurate. Member checking with each participant helped to ensure data was accurate and interpreted as the participant intended.

Kawasaki, Kojima, and Akamatsu (2016) indicated that research validity ensures research finding is both credible and confirmable. Researchers use data saturation, member checking, and recorded data to validate research findings in qualitative research (Hussein, 2015). A researcher reaches data saturation when there is no additional information from data collected during the research and interview procedure, and at that point, the interview process stops (Fusch \& Ness, 2015).

The primary objective of qualitative research is to reduce researcher bias through research designs. A case study's validity involves having clear evidence of credible and confirmable information for data interpretation. The confirmability evolves through methodological triangulation of various data sources, such as interviews, member checking, and companies' achieved documents (Nelson, 2016). I used a combination of these validation techniques to demonstrate credibility. 
Credibility in research using an interview protocol, audit trail, member checking, saturation, and triangulation enhances trustworthiness (Gonzalez, Rowson, \& Yoxall, 2015). Credibility depends more on the richness of information gathered than the volume of data collected (Fusch \& Ness, 2015). Qualitative research findings are based on more than one data collection method that enhances the study's validity and credibility (Roulston, 2016). Researchers use member checking to allow participants to approve, correct or extend the researcher's interpretation of the experiences recorded in the interview transcript (Marshall \& Rossman, 2016). Member checking is useful for the preliminary performance of interview data for accuracy. Data triangulation is another powerful technique that facilitates data validation through verification from two or more sources. Triangulation is a method researcher uses in a case study to check and establish validity to arrive at consistency across data sources (Baillie, 2015). I conducted member checking and triangulation processes. Data sources for the study were semistructured interviews, company documents, and archival records. The use of more than one procedure was to confirm that data analysis is credible and trustworthy (Kornbluh, 2015).

Confirmability connects to the participant's authentic reflections without the researcher's perspective interfering with the research outcomes (Hays, 2016). Confirmation requires the comparison of data gathering from multiple sources through verification of data. Validating the research study using multiple data sources will help assess the confirmability of the findings (Hussein, 2015). Researchers ensure confirmability by verifying findings to ensure that the results accurately reflect the participant's experience and understandings (Bloomberg \& Volpe, 2015). I used the interview protocol, data triangulation, data saturation, and member checking, which enhance confirmability.

\section{Findings}

Through interviews with four small business owners who successfully motivated and retained talented employee, I identified three themes and presented them in the following pages. The interviews lasted approximately 30 minutes each. The conceptual framework that I used was transformational leadership theory (Burns, 1978). Burns introduced inspirational motivation as a motivational factor that enhances subordinates' efforts to achieve an organizational goal; a leader who motivates and gives rewards to their followers improves employees' efforts to increase profits (Northouse, 2016). The conceptual framework aligns with existing literature and themes generated in the findings. Each theme suggested a transformational strategy a small business owner can use to motivate and retain their sales associate to increase business profits. I also reviewed available information from the company websites and social media and direct observation.

Table 1 shows the demographic information about the four small business owner participants. All four interviewees had a combined total of 58 years of experience as business leaders in Texas's small business industry. 
Table 1. Demographic information about the small business owners.

\begin{tabular}{ccccc}
\hline Characteristics & Case 1 & Case 2 & Case 3 & Case 4 \\
\hline Business Owner: Code name & P1 & P2 & P3 & P4 \\
Age & 49 & 60 & 35 & 46 \\
Country of birth & Nigeria & Nigeria & USA & USA \\
Highest level & Masters' & Bachelors' & Bachelors' & Doctorate \\
Education & Degree & Degree & Degree & Degree \\
Length in current Organization & 20 & 16 & 12 & 10 \\
Years of experience as Small business \\
owners
\end{tabular}

The findings showed the strategies small business owners use to motivate and retain sales associates to increase business profits. The interview questions' answers provided a conceptual framework, literature review findings, and triangulation, which helped me identify themes during data analysis.

\section{Theme 1: Provide Financial Incentives}

Motivation is the process that contributes to employees or individuals in the effort toward attaining a goal (Novianty \& Evita, 2018). Business leaders use financial incentive programs in various forms of direct compensation beyond salary to increase employees' motivation toward achieving organizational goals and improve performance (Novianty \& Evita, 2018). The participants in this study P1, P2, and P3 agreed that employees' motivation through various financial incentives would contribute to employee's retention.

A fundamental employee need is to be paid well for hard work. The exchange between labor and adequate pay has long been the standard of reinforcement at work. Many employees will argue little else matters beyond good pay. Arguably, pay, with any additional incentives, works to motivate employee retention. Pay incentives, praise, bonuses, and any other form of recognition go a long way to strengthen the psychological contract between an employer and employee. In this study, the organizational leaders all agreed on adequate pay's vital nature, underscoring that low income is generally an excellent incentive to leave an organization. Employees who leave due to inadequate compensation will likely gain meaningful employment with the competition, strengthening a different business that will inevitably create challenges for all other businesses struggling to remain active in the competitive market. Treating employees well ensures fair access to the competitive market and leads to employee longevity, increased customer loyalty, and more significant business sustainability. A satisfied employee, resulting from being appropriately paid, may prove to open communication lines, and secure an employee for a longer term of employment.

Nemeckova (2017) suggested that financial incentives, such as pay increases, pension schemes (401 k), and other bonuses are significantly crucial to organizations to improve employee motivation and retention in the workplace. Addi- 
tionally, Nemeckova argued that when employees display a sense of happiness and satisfaction, it will increase their morale, work performance, and productivity level. Well-motivated employees perform better, and the organization with such employee attributes has a higher efficiency in achieving the company's objectives and goals (Krstic, Obradovic, Terzic-Supic, Stanisavljevic, \& Todorovic, 2019). Transformational leadership was the conceptual framework for this study. Researchers have defined leadership differently. Ming, Tee, and Hua (2018) stated that a leader is an individual who could influence his or her subordinates to achieve the goal and vision of the organization. A transformational leader can influence and enhance followers' morale, motivation, and job performance (Ming et al., 2018). A motivational strategy relates to the dynamic force to stimulate individual behavior. Some leaders bring a significant positive change in their followers and organizations by using inspirational and individualized motivation to achieve more exceptional results (Busse \& Czekala, 2018).

All four participants explained that the transformational leadership style inspired and motivated employees to achieve various organizational objectives. Some business leaders and managers use incentives to encourage and influence employees for optimal profitability, increased productivity, and employee retention (Ming et al., 2018). Northouse (2016) argued that business leaders might achieve organizational success using financial incentive programs with the employees. Table 2 contains the participants' statements about employee motivation and incentives programs.

Theme Two Job Satisfaction

All four business leaders acknowledged employees' job satisfaction as a critical

Table 2. Theme 1: provide financial incentives.

\section{Participant Comments}

P1 We give bonuses and other incentives that can motivate employees' performance. Ultimately, this process also enhances the cordial relationship between employees and our customers. It is a strategy that helps build a relationship with our clients.

P2 As part of incentives, we train our employees, as well as inviting Outside professionals to coach our staff on other effective methods of improving their job performance in our company. Sometimes, I take my staff out to meeting clients face-to face in the field to demonstrating and establishing good customer service representation that could bring better workplace performance.

P3 In our organization, employees are compensated through various incentives programs, such as salary increases, bonuses, team trips, and outings where everyone comes together to have fun! At the same time, we use that opportunity to get to know one another on a personal level. Our company is like a family that have each other's back, and we see this approach as part of our company's culture that increases our company growth.

P4 Incentives program help in motivating staff. We have what we called "Happy Hours" where all the staff members come together for dinner and have some fun. Also, we have a big Christmas party every year; and this year 2019, I am taking my staff for our tenth anniversary out of town to have a good time together. I try to motivate my employees the way I want to be treated, and I do motivate them positively, which does enhance workplace performance in my company. 
component motivating people to perform effectively in the workplace. P4 stated that he does not have a survey to measure performance. However, they provide 6-month evaluations with both employers' and employees' feedback. P4 also said he used internal feedback as a vital tool that helps build a good relationship between employers and employees. P3 indicated that the workplace environment influences employee productivity and job satisfaction.

In this study, all participants indicated that a critical factor in their organizations' success was their effort to draw the best from employees through guidance, open communication, and reinforcement. Good communication reciprocated between organizational leaders and the various stakeholders in the company genuinely helped create bonds characterized by mutual admiration, leading to a desire to perform well, improve productivity, and care about outcomes within the company, ultimately establishing a greater sense of job satisfaction. Employees demonstrated they had a stake in the organization's success and, if rewarded, recognized, and understood by leadership, would act reasonably, and remain committed to the organization. Employers require a great effort to foster a healthy relationship with employees to develop a mutually respectful and trusting relationship, characterized by improved employee retention and a culture of unity within the company. A key element of job satisfaction results from careful attention and measuring of factors that contribute to job satisfaction, such as infrequent absenteeism, eagerness to complete work tasks, frequent positive feedback, expedited resolves as issues arise, and an individualized approach to personal communication. All efforts on behalf of leadership to strengthen a mutual commitment to the company, enhanced by job satisfaction, will help keep a company thriving within a competitive marketplace.

A well-designed workplace attracts people to the business. Wnuk (2017) found that employee job satisfaction offers small business owners and management staff the ability to structure the work environment. The most valuable, loyal, and experienced employees are retained for a more extended period. Wnuk argued that job satisfaction increases employees' effectiveness and decreases employee turnover intention. Huang and Chih-Hao (2016) ascertained that job satisfaction and other rewards should be a powerful tool in sharpening employees' attitudes toward workplace performance. Job satisfaction is a complex construct, and several types of relationships form job satisfaction. Low job satisfaction may be a negative factor in employee turnover (Huang \& Chih-Hao, 2016). Valaei and Jiroudi (2016) agreed that job satisfaction positively influences employees' high productivity and retention. Job satisfaction and performance are useful to employees' development, and business leaders and management should provide a plan that could enhance employee job satisfaction for the overall success of the organization (Valaei \& Jiroudi, 2016).

Some business leaders use job satisfaction techniques to establish a better working atmosphere to increase employees' morale and job performance. All four participants, P1, P2, P3, and P4, agreed that employee's job satisfaction 
helped improve business growth and profitability. Table 3 includes direct statements from each participant related to employees' job satisfaction.

\section{Theme 3: Enhance Job Training}

Job training gives employers and employees advantages for successful engagement of business operations. All four participants in this study stated that job training is good for business improvement. Lin and Hsu (2017) found that on-the-job training and expanding the employees' learning experience should encourage business leaders to promote a healthy workplace environment. On-the-job-training could enhance employees' knowledge and improve the organization's profitability (Lin \& Hsu, 2017). Lin and Hsu argued that on-the-job training could enhance employees' organizational commitment and reduce employees' turnover intention. Also, motivating and retaining employees could increase the economic growth of the organization. Equally, on-the-job-training could also reduce accidents on the job and promote workplace safety and harmony to increase job satisfaction. A business leader who applies appreciative inquiry to identify each employee's needs, particularly as it relates to training, with the intent of preparing the employee to grow in the company, is a tremendous

Table 3. Theme 2: increase job satisfaction.

\section{Participant Comments}

P1 I study employees' job satisfaction on an individual bases and use of questionnaires. On individual basis, I studied each employee on through their attendance to work. For instance, if they are happy, I believe they should be coming to work regularly to come and do their job. Likewise, when they are not coming on a regular basis, it means maybe something is wrong; either they are not satisfied with the job, or they are going through some emotional problem. On the other hand, sometimes, I gave out questionnaires to my staff to fill-out and to evaluate them. Through their response, I will know which areas to improve and assist them.

P2 Sometimes, the way my employees come to work; for example, showing up early to work and immediately starting to book up some appointments with clients to show that they are happy and satisfied in their job assignment. Also, I train my staff to improve performance. With the flexibility and independence of my staff, they feel satisfied to work in my company.

P3 Well, one example of employee job satisfaction is job security, good pay, and a good environment. A place you are doing your business matters a lot. For example, this office we are sitting in now, we just moved in here not long ago, it is a very conducive environment for the staff and our clients. Since we moved in here, employees are happy and satisfied, and we are making progress in our business. Also, we compensated our staff with salary increases, bonuses, and team trips, which makes them happy working in our company as well as retaining them.

P4 We do six months evaluations on our staff. Though, we do not do a survey or questionnaire, something we should be doing. However, we do ask our staff for some directives or opinions about our progress, and we expect feedback from them. We see internal feedback as a vital tool that helps us build a good relationship between the employers and employees. A lot of employees feel a sense of belonging and satisfaction when they have a good relationship with the employers. Also, we train our staff and increase their salary to motivate them. Through motivation, it helps to increase employees work performance. 
incentive to remain with the company. The organizations involved in the study offered a range of incentivized training options for employees, including trade preparation and other educational programs such as degree offerings in exchange for a commitment to stay with the company. These incentives help prepare the employee for the current workforce while providing the employee with competitive skills that aid in career building within the company and beyond.

A key element in offering job training is to help secure a commitment from employees to support their academic and training growth while contributing to the company's credentials, essentially benefiting both parties to advance their interests. Ideally, both parties recognize this and work collaboratively toward their joint interests. Participant P1 indicated that the use of modern technology, such as the internet, email, conference calls, and webinars, helps improve employee's job training more effectively. Participant P2 added that he trains his employees as well as invites outside professionals to educate and coach his staff on the new market techniques. Park, Hye-Seung, and Eun-Jee (2018) suggested that business leaders and managers should support and promote employee motivation and on-the-job training to enhance employee knowledge, gain more confidence, skills, and experience necessary to work more competently. Organizational leaders expect that any knowledge and skills acquired through job training will transfer to the workplace, resulting in increased and improved job performance.

Park et al. (2018) confirmed that job training has positive outcomes for organizational productivity. Thus, with increased employee engagement in organizational development activities, the more this knowledge aids in employee productivity. Demiral (2017) pointed out that employees' training can significantly influence an organization's success through different models, such as learning innovation, employees' motivation, and retention. Demiral listed some of the advantages of employees' job training as 1) improved productivity, 2) increased job satisfaction and career advancement, and 3) increased motivation. Another benefit of job training, as explained by Demiral is that small businesses or larger organizations investing in employees' training programs can gain a competitive edge compared to their counterparts with no training services. Consequently, this competitive advantage is achievable by transforming the organization into a learning organization and environment, teaching and training the workforce for long-term sustainable competitiveness, and increasing employees' skills.

Demiral (2017) and Ocen Francis and Angundaru (2017) stressed that job training raises the potential for increased profitability. The authors further argued that due to the rapidly changing business model and the current expansion of the global economy, technologies consistently enhance organizational training initiatives. P1 said that in his business, he teaches his staff about the e-commerce business, and they use modern technologies in their business operations. P2 echoed the advantages of job training and stated that he teaches his staff on the new scope of their business model and invites other professionals to coach his 
employees on the latest market techniques. P3 stated that as a business leader, you must train and retain your staff because they are the company's active representatives, which could lead to keeping them for an extended period. P4 highlighted that employees' job training is an excellent technique to improve business productivity. Regardless of cost and resource use, job training remains beneficial to business performance. Table 4 consists of a summary of the statements made by each participant on enhance job training.

\section{Application to Professional Practice}

The result of this study could assist current and future small business owners in executing strategies to motivate and retain their sales associates to increase business profits. The results exposed three themes: 1) provide financial incentives, 2) increase job satisfaction, and 3) enhance job training. One tenet of Burns (1978) transformational leadership theory was inspirational motivation, which implied that leaders communicate a commitment to a shared vision of the organization (Northouse, 2016). Some small businesses have closed due to leadership failures. Business leaders should apply strategies that can inspire, motivate, and enhance followers' self-interest, to achieve their vision and objectives (Ugwu, Enwereuzor, \& Orji, 2016).

This study's specific business problem implied that some small business owners lack strategies to motivate and retain their sales associates to increase business profits. Business leaders must commit to their subordinates' needs, empowering, engaging, encouraging, and rewarding them for achieving beyond what is expected (Ugwu et al., 2016). In general, a leader is an individual who has the ability or can influence, motivate and contribute to the effectiveness of the group or organization, to improve performance (Marcoux, Guihur, \& Koffi, 2016).

Table 4. Theme 3: Enhance job training.

\section{Participant Comments}

P1 Use of innovative technology is important in today's business. As an entrepreneur (business owner), I teach my employees about e-commerce business. Use of technology has helped us to create a flexible work environment and increase workplace performance. For example, software services, Skype video and conference calling, internet, email, webinars are important tools that have helped us in our business operations.

P2 As, the business owner, I do train my employees, as well as inviting and outsourcing professionals who come and help teach and coach our staff on a better strategy and new market techniques to improving our services on the day-to-day operations of our business.

P3 We train and retain our staff properly because they are the representatives of our company. Also, training them will help to retain them for a longer period. We train our employees for optimal performance in all areas of our business operations.

P4 The, biggest issues, first, retention cost so much money to train employees. Though, recently, we trained one staff into a new position with salary increased. We try to advance within our company when possible, that is giving promotion to those who merit it. 
Leaders who display transformational leadership traits effectively change employee behavior to achieve organizational goals (Kim \& Shin, 2017). Kim and Shin further argued that transformational leaders motivate employees through incentive benefits. As noted in the findings motivating employees through incentive programs would improve workplace performance, increase profits, increase employees' retention, and decrease turnover. Inspirational motivation denotes a leader's ability to inspire and mentor followers (Louw, Muriithi, \& Radloff, 2017), achieved through communication skills, mentoring, corrective action, and risk-taking. Small business owners should emulate and focus on efficiency and ensure their strategies are implemented in different management levels (Louw et al., 2017).

By following this study's recommendations, small business owners could improve their business operations by implementing effective strategies that would increase business profits and long-term sustainability. Additionally, the application of this study's findings may also reduce ineffective management of employees that lead to business failures. The findings can serve as a practical guide to some failing small business leaders that lack strategies to motivate their employees. Current and future small business owners could also use employees' motivation strategies to improve business sustainability and profitability.

The results of this study could help improve the small business leader's strategy on employee's motivation and retention for optimal business profitability. Positive business leadership performance could lead to business growth, strengthen employment rates, promote business development, fuel local and state economies, and enhance employment opportunities for local citizens. The local and state economies can continue to move forward, especially when community members have a job and steady income, assist the family financially, contribute to taxes to increase local and state revenues, and stabilize economic growth. This study's findings could contribute to social change by helping other small business owners implement motivation and retention strategies that increase business profits. Business sustainability supports both local and state economy; and fosters an optimum distribution of resources in the community (Marina \& Wahjono, 2017). Appropriately allocated community resources may strengthen small business leader's commitment to fuel local economics, generating local economic growth, while improving the quality of life for families, communities, and societies (Marina \& Wahjono, 2017).

\section{Recommendations for Action}

The purpose of this qualitative multiple case study was to explore strategies that small business owners use to motivate and retain sales associates to increase business profits. Based on this study's findings, I recommend several actions that current and future small business owners can utilize to increase employees' motivation and retention strategies. I identified three recommendations that could benefit current and prospective small business owners' success: 1) provide financial incentives, 2) increase job satisfaction, and 3) enhance job training. The first 
recommendation is providing financial incentives to employees and is essential to promote employees' motivation for business growth, and retention of employees. Business leaders should take the advantages and benefits of employees' motivation through incentives programs to improve business performance. Sudiardhita, Mukhtar, Hartono, Herlitah, Sariwulan, and Nikensari (2018) stated that an organizational leader should maintain its workforce by utilizing available resources at their disposal to effectively and efficiently achieve the organizational vision. Leaders who apply motivational philosophy and practice can improve productivity and work quality (Sudiardhita et al., 2018). Motivated and satisfied employees are an asset to the company and can impact the organizations' productivity and performance (Bhuyan \& Goswami, 2017). Job satisfaction is positively and significantly related to employee performance; small businesses and larger organizations should try to enhance employee job satisfaction.

The second recommendation is to increase job satisfaction. Business owners can use this study to implement a strategy that will promote employee's job satisfaction, such as pay increases, and other reward programs. Job satisfaction is achievable if there is a positive rewards system established by the leaders and management (Hafeez, 2019), and satisfied employees give their full effort to achieve the company's goal. Business leaders need to develop and improve employee retention to avoid employees' turnover intention. And lack of leadership, poor management and communication, and low pay can cause an employee to leave their jobs at any time if dissatisfied. Likewise, employee engagement and communication are crucial between employers and employees to enhance business success (Hafeez, 2019). Therefore, business leaders and managers need to improve employees' commitment and communication for sustainable business growth.

The third recommendation is enhancing job training. The current job market requires educated and experienced, skilled, and innovative professionals. Business owners need to establish a policy and strategy that would promote periodic job training to meet talented employees' present job market. The job market requires educated and experienced professionals with skills in innovation. Conversely, business leaders should invest in increasing innovation training among their workers to have a competitive edge. Alvarez and Carrasco (2016) emphasized that training employees on the newly acquired office machines and other modern equipment can speed up business operations.

\section{Recommendations for Further Research}

I conducted a qualitative multiple case study on the strategies that small business owners use to motivate and retain their sales associates to increase business profits. The strategies found are 1) provide financial incentives 2) increase job satisfaction, and 3) enhance job training. The population of this study consisted of four cases in Texas State of the United States. The limitations of this case study were that interviewing a small population knowledgeable about a phenomenon; the findings generated from this confined group may not produce gene- 
ralizations about an entire industry or geographic area.

Future researchers might use a mixed-method and involve interviews with a much larger population. The quantitative research method can also be useful to test hypotheses and the correlation between the given themes and motivation strategies recognized in this study. Quantitative research can also yield more extensive data analysis and compare the external validity to different environments.

Further investigation into the impact of incentives as a motivator for retaining employees, specifically, what incentives are most effective, would shed light on building relationships with employees through appreciation for work well done. Identifying key ways to increase employee job satisfaction at various work environments may help a broader population of businesses to establish a culture of harmony between employers and employees. While strategizing appropriate job training opportunities for employees in which the skill sets grow and support the company are essential, significantly while enhancing job satisfaction and fortifying incentives to keep employees.

\section{Conclusion}

Employees' motivation has a positive and significant impact on employee performance in the small business sector and larger organizations. The usual assumption is that the primary motivation is salary and other incentives, such as monetary rewards, bonuses, and many more. Motivation is a set of factors that stimulate and directly guide people to increase their efforts to achieve a set goal. Business leaders' inability to motivate and retain their employees can lead to low profitability, and sustainability from failure to retain employees, resulting in employee turnover. Sustaining and growing a small business require a leader who has the capacity and managerial experience to build a successful business that can improve performance and profitability. Business leaders must integrate the value and importance of sustainability into their strategic leadership decision-making. Thus, employee motivation and retention are vital for the next generation of businesses.

\section{Conflicts of Interest}

The author declares no conflicts of interest regarding the publication of this paper.

\section{References}

Abdullah, Q. D. L., \& Varatharajoo, K. D. R. (2017). Transformational Leadership and Its Functionality in Arts Organization. International Journal of Business and Society, 18, 710-717. http://www.ijbs.unimas.my

Alatawi, M. A. (2017). The Myth of the Additive Effect of the Transformational Leadership Model. Contemporary Management Research, 13, 19-30.

Alvarez, G., \& Carrasco, R. (2016). Measuring the Impact of on the Job Training on Job 
Mobility. Revista de Economía Aplicada, 24, 5-25. http://www.researchgate.net

Anitha, J., \& Begum, F. N. (2016). Role of Organizational Culture and Employee Commitment in Employee Retention. ASBM Journal of Management, 9, 17-28. https://www.asbm.ac.in/asbmjournal/

Apostolopoulos, N., \& Liargovas, P. (2016). Regional Parameters and Solar Energy Enterprises: Purposive Sampling and Group AHP Approach. International Journal of Energy Sector Management, 10, 19-37. https://doi.org/10.1108/IJESM-11-2014-0009

Avani, A., \& Gulzar, S. (2016). Impact of Employees' Participation on Job Satisfaction Evidence from Karacht's Tertiary Education Sector. Indian Journal of Commerce and Management Studies, 7, 47-52.

Azeez, R. O., Jayeoba, F., \& Adeoye, A. O. (2016). Job Satisfaction, Turnover Intention and Organizational Commitment. Journal of Management Research, 8, 102-114. http://www.jmgtr.com/index.php/jmr

Baillie, L. (2015). Promoting and Evaluating Scientific Rigor in Qualitative Research. Nursing Standard, 29, 36-42. https://doi.org/10.7748/ns.29.46.36.e8830

Bamdale, A. J., Girei, A. A., \& Barwa, T. M. (2017). Leadership Styles and Workers' Performance in Small and Medium Scale Industries in Adamawa State, Nigeria: A Research Model. Journal of Economic Development, Management, IT, Finance, and Marketing, 9, 14-23.

Baskar, L., \& Rajkumar, K. R. (2015). A Study on the Impact of Rewards and Recognition on Employee Motivation. International Journal of Science and Research, 4, 1644-1648. https://doi.org/10.21275/v4i11.NOV151549

Bhuyan, S., \& Goswami, M. (2017). Determinants of Employee Motivation in Assam Carbon Products Limited: A Case Study. Sumedha Journal of Management, 6, 47-53. http://www.indiajournal.com

Bindu, H. (2017). Factors Influencing Employee Retention-The Study in Selective Service Sector Organizations. Vidwat, 10, 25-30. http://www.vidwat.com

Bloomberg, L. D., \& Volpe, M. (2015). Completing Your Qualitative Dissertation: A Roadmap from Beginning to End. Thousand Oaks, CA: Sage.

Brennan, P. F., \& Bakken, S. (2015). Nursing Needs Big Data, and Big Data Needs Nursing. Journal of Nursing Scholarship, 47, 477-484. https://doi.org/10.1111/jnu.12159

Bucata, G., \& Rizescu, A. M. (2017). The Role of Communication in Enhancing Work Effectiveness of an Organization. Land Forces Academy Review, 22, 49-57.

https://doi.org/10.1515/raft-2017-0008

Burns, J. M. (1978). Leadership. New York, NY: Harper \& Row.

Busse, R., \& Czekala, L. (2018). Superheroes at Work-Revealing the Bright and the Dark Side of Transformational Leaders. Advances in Management, 11, 1-15. https://www.emerald.com/insight/publication/issn/0972-7981

Cairney, P., \& St. Denny, E. (2015). What Is Qualitative Research (Bloomsbury). International Journal of Social Research Methodology, 18, 117-125. https://doi.org/10.1080/13645579.2014.957434

Çakir, O., \& Kozak, M. A. (2017). Designing an Effective Organizational Employee Motivation System Based on ABCD Model for Hotel Establishments. Tourism and Hospitality Management, 23, 69-86. https://doi.org/10.20867/thm.23.1.6

Chen, S. P., \& Mykletun, R. J. (2015). Beyond Post-Downsizing Organizational Injustice and Counterproductive Work Behaviors: Antecedents and Consequences of Learnt Helplessness. International Journal of Business Management, 10, 1-14. 
https://doi.org/10.5539/ijbm.v10n6p1

David, S. L., Hitchcock, J. H., Ragan, B., Brooks, G., \& Starkey, C. (2016). Mixing Interviews and Rasch Modeling: Demonstrating a Procedure Used to Develop an Instrument That Measures Trust. Journal of Mixed Methods Research, 12, 75-94. https://doi.org/10.1177\%2F1558689815624586

Delaney, M. L., \& Royal, M. A. (2017). Breaking Engagement Apart: The Role of Intrinsic and Intrinsic Motivations in Engagement Strategies. Industrial and Organizational Psychology, 10, 127-140. https://doi.org/10.1017/iop.2017.2

Demiral, O. (2017). Effects of Training on Employee Job Satisfaction and Achievement: Train to Gain Evidence from Manufacturing Businesses in Turkey/ Meslekiegitimin calisanlarin is tatminine ve basarisina etkisi: Turkiye deki imalatisletmeleri uzerine kazanmak icin egit bulgulari. Business \& Management Studies: An International Journal, 5, 765-785. https://doi.org/10.15295/bmij.v5i3.157

Devi, U., Y, \& Krishna, M., V. (2016). Impact of Human Resources Management Practices on Employee Turnover: An Empirical Study with Special Reference to IT Sector. Journal of Strategic Human Resource Management, 5. https://www.publishingindia.com/jshrm/

Dhanpat, N., Madou, F. D., Lugisani, P., Mabojane, R., \& Phiri, M. (2018). Exploring Employee Retention and Intention to Leave within a Call Center. SA Journal of Human Resource Management, 16, Article No, a905. https://doi.org/10.4102/sajhrm.v16i0.905

Fiaz, M., Su, Q., Ikram, A., \& Saqib, A. (2017). Leadership Styles and Employees' Motivation: Perspective from an Emerging Economy. The Journal of Developing Areas, 51, 143-156. https://doi.org/10.1353/jda.2017.0093

Fusch, P. I., \& Ness, L. R. (2015). Are We There Yet? Data Saturation in Qualitative Research. The Qualitative Report, 20, 1408-1416. https://doi.org/10.46743/2160-3715/2015.2281 https://doi.org/10.46743/2160-3715/2015.2281

Fusch, P., Fusch, E., \& Ness, L. R. (2018). Denzin's Paradigm Shift. Revisiting Triangulation in Qualitative Research, 10, 19-32. https://doi.org/10.5590/JOSC.2018.10.1.02

Gadalla, E., Abosag, I., \& Keeling, K. (2016). Second Life as a Research Environment: Avatr-Based Focus Groups (AFG). Qualitative Market Research, 19, 101-114. https://doi.org/10.1108/QMR-08-2015-0070

Galvin, R. (2015). How Many Interviews Are Enough? Do Qualitative Interviews in Building Energy Consumption Research Produce Reliable Knowledge? Journal of Building Engineering, 1, 2-12. https://doi.org/10.1016/j.jobe.2014.12.001

Gill, M., Bagshaw, S. M., McKenzie, E., Oxland, P., Oswell, D., Boulton, D., \& Selfor, H. T. (2016). Patient and Family Member-Led Research in the Intensive Care Unit: A Novel Approach to Patient-Centered Research. PLoS ONE, 11, e0160947. https://doi.org/10.1371/journal.pone.0160947

Gonzalez, V., Rowson, J., \& Yoxall, A. (2015). Development of the Variable Dexterity Test: Construction, Reliability and Viability. International Journal of Therapy \& Rehabilitation, 22, 174-180. https://doi.org/10.12968/ijtr.2015.22.4.174

Gunasekara, V. M. (2018). Impact of Motivation on Executive Level Employees' Job Performance: An Empirical Study of Listed Leasing Companies in Sri Lanka. International Journal on Global Business Management \& Research, 7, 67-74. http://www.jgbm.org/

Gutierrez-Wirsching, S., Mayfield, J., Mayfield, M., \& Wang, W. (2015). Motivating Language as a Mediator between Servant Leadership and Employee Outcomes. Management Research Review, 38, 1234-1250. https://doi.org/10.1108/MRR-01-2014-0009 
Hafeez, M. M. (2019). Influence of Thriving and Job Satisfaction on Turnover Intention: Mediating Role of Job Satisfaction. International Journal of Information, Business and Management, 11, 1-8.

Hays, D. G., Wood, C., Dahl, H., \& Kirk-Jenkins, A. (2016). Methodological Rigor in Journal of Counseling \& Development Qualitative Research Articles: A 15-Year Review. Journal of Counseling \& Development, 94, 172-183.

https://doi.org/10.1002/jcad.12074

Huang, W., \& Chih-Hao, S. (2016). The Mediating Role of Job Satisfaction in the Relationship between Job Training Satisfaction and Turnover Intentions. Industrial and Commercial Training, 48, 42-52. https://doi.org/10.1108/ICT-04-2015-0029

Hussein, A. (2015). The Use of Triangulation in Social Sciences Research: Can Qualitative and Quantitative Methods Be Confined? Journal of Comparative Social Work, 4, 106-117. https://journals.uis.no/index.php/JCSW https://doi.org/10.31265/jcsw.v4i1.48

Jalalkamali, M., Ali, A. J., Hyun, S. S., \& Nikbin, D. (2016). Relationships between Works Values, Communication Satisfaction, and Employee Job Performance. Management Decisions, 54, 796-814. https://doi.org/10.1108/MD-01-2015-0003

Justin, G., Kaitlynn, L., Bharat, M., \& Jitendra, M. (2017). Being More Productive. Advances in Management, 10, 1-6. http://www.emeraldgrouppublishing.com/journal/jamr

Kang, D. U., Gun, J. Y., \& Lee, S. (2016). Disentangling the Effects of the Employee Benefits on Employee Productivity. Journal of Applied Business Research, 32, 1447-1458. https://doi.org/10.19030/jabr.v32i5.9771

Kang, M., \& Sung, M. (2017). How Symmetrical Employee Communication Leads to Employee Engagement and Positive Employee Communication Behaviors. Journal of Communication Management, 21, 82-102.

https://doi.org/10.1108/JCOM-04-2016-0026

Kawasaki, Y., Kojima, Y., \& Akamatsu, R. (2016). Barriers to Accurately Measuring Patient's Dietary Intake in Hospitals Using the Visual Estimation Method: A Qualitative Research. International Journal of Health Care Quality Assurance, 29, 835-845. https://doi.org/10.1108/IJHCQA-04-2016-0042

Khan, Z. (2016). Determinants of a Successful Cross-Border Knowledge Transfer in Franchise networks. Journal of Asia Business Studies, 10, 148-163. https://doi.org/10.1108/JABS-05-2015-0052

Kihn, L. A., \& Ihantola, E. M. (2015). Approaches to Validation and Evaluation in Qualitative Studies of Management Accounting. Qualitative Research in Accounting \& Management, 12, 230-255. https://doi.org/10.1108/QRAM-03-2013-0012

Kim, S., \& Shin, M. (2017). The Effectiveness of Transformational Leadership on Empowerment. Cross Cultural \& Strategic Management, 24, 271-287. https://doi.org/10.1108/CCSM-03-2016-0075

Klenke, K. (2016). Qualitative Interviewing in Leadership Research. In Qualitative Research in the Study of Leadership (pp. 123-150). Bingley: Emerald Group Publishing Limited. https://doi.org/10.1108/978-1-78560-651-920152007

Klopotan, I., Mjeda, T., \& Kurečić, P. (2018). Exploring the Motivation of Employees in a Firm: A Case Study. Business Systems Research, 9, 151-160. https://doi.org/10.2478/bsrj-2018-0012

Kornbluh, M. (2015). Combatting Challenges to Establishing Trustworthiness in Qualita- 
tive Research. Qualitative Research in Psychology, 12, 397-414.

https://doi.org/10.1080/14780887.2015.1021941

Krstic, M., Obradovic, V., Terzic-Supic, Z., Stanisavljevic, D., \& Todorovic, J. (2019). Leadership and Motivation among Employees in Health-Care Facilities in Serbia. Management: Journal of Sustainable Business and Management Solutions in Emerging Economies, 24, 33-43. https://doi.org/10.7595/management.fon.2018.0022

Kubica, I., \& Szarucki, M. (2016). Exploring Employee Motivation in Polish Family Firms. Case of Retail Sector. Business Management and Education, 14, 194-209. https://doi.org/10.3846/bme.2016.333

Kumar, V., \& Pansari, A. (2016). Competitive Advantage through Engagement. Journal of Marketing Research, 53, 497-514. https://doi.org/10.1509/jmr.15.0044

Kuranchie-Mensah, E., \& Amponsah-Tawiah, K. (2016). Employee Motivation and Work Performance: A Comparative Study of Mining Companies in Ghana. Journal of Industrial Engineering and Management, 9, 255-309. https://doi.org/10.3926/jiem.1530

Kushwaha, D. W., \& Lodhwal, R. K. (2016). Factors Influencing Employee Motivation in Indian University: A Case Study of Banaras Hindu University. Journal of Organization and Human Behavior, 5. https://doi.org/10.21863/johb/2016.5.2.031

Kuznetsova, N. V., Sinitsina, O. N., Gafurova, V. M., Pavluhina, M. V., Salyaeva, T. V., \& Puzankova, E. A. (2017). Motivation as Factor of Improving Efficiency of Trade Company Operations. European Research Studies, 20, 319-337. https://doi.org/10.35808/ersj/644

Lee, G., Lee, M., \& Sohn, Y. (2017). High-Performance Work Systems and Firm Performance: Moderating Effects of Organizational Communication. Journal of Applied Business Research, 33, 951-962. https://doi.org/10.19030/jabr.v33i5.10018

Lin, S., \& Hsu, C. (2017). A Study of Impact on-Job Trading on Job Performance of Employees in Catering Industry. International Journal of Organizational Innovation (Online), 9. http://www.emeraldgrouppublishing.com/journal/ijoa

Louw, L., Muriithi, S. M., \& Radloff, S. (2017). The Relationship between Transformational Leadership and Leadership Effectiveness in Kenyan Indigenous Banks. SA Journal of Human Resource Management, 1, Article No. a935. https://doi.org/10.4102/sajhrm.v15i0.935

Malik, M., Wan, D., Ahmad, M. I., Naseem, M. A., \& Rehman, R. U. (2015). The Role of LMX in Employee's Job Motivation, Satisfaction, Empowerment, Stress and Turnover: Cross Country Analysis. Journal of Applied Business Research (JABR), 31, 1897-2000. https://doi.org/10.19030/jabr.v31i5.9413

Malik, S. Z., Saleem, M., \& Naeem, R. (2016). Effect of Leadership Styles on Organizational Citizenship Behavior in Employees of Telecom Sector in Pakistan. Pakistan Economic and Social Review, 54, 385-406. http://www.pu.edu.pk

Manning, G., \& Curtis, K. (2012). The Art of Leadership (4th ed.). New York, NY: McGraw-Hill.

Marcoux, G., Guihur, I., \& Koffi, V. (2016). Employees' Contribution to the Succession Process of Family Small and Medium-Sized Businesses: Conceptual Model and Research Agenda. Management Review: An International Journal, 11, Article No. 70. https://www.onlinelibrary.wiley.com/journal/14682370

Marina, A., \& Wahjono, S. I. (2017). Business Ethics for Business Sustainability in Muhammadiyah Hospital: Evidence from Ponorogo, Indonesia. Journal of Indonesian Economy and Business, 32, 178-189. https://doi.org/10.22146/jieb.17146

Marshall, C., \& Rossman, G. B. (2016). Designing Qualitative Research (6th ed.). Thou- 
sand Oaks, CA: Sage Publications

Matza, L. S., Boye, K. S., Stewart, K. D., Curtis, B. H., Reaney, M., \& Landrian, A. S. (2015). A Qualitative Examination of the Content Validity of the EQ-5D-5L in Patients with Type 2 Diabetes. Health \& Quality of Life Outcomes, 13, Article No. 192. https://doi.org/10.1186/s12955-015-0373-7

McManus, J., \& Mosca, J. (2015). Strategies to Build Trust \& Improve Employee Engagement. International Journal of Management \& Information Systems, 19, 37-42. https://doi.org/10.19030/ijmis.v19i1.9056

Moreland, J., \& Apker, J. (2015). Conflict and Stress in Hospital Nursing: Improving Communicative Responses to Enduring Professional Challenges. Health Communication, 31, 815-823. https://doi.org/10.1080/10410236.2015.1007548

Morrison, J., Clement, T., Nestel, D., \& Brown, J. (2016). Under Discussed, Underused and Underreported: Pilot Work in Team-Based Qualitative Research. Qualitative Research Journal, 16, 314-330.

Motlou, R. G., Singh, S., \& Karodia, A. M. (2016). An Evaluation of the Impact of Job Satisfaction on Employee Retention in Lonmin Rowland Shaft North West Province. Kuwait Chapter of the Arabian Journal of Business and Management Review, 5, 15-49. https://doi.org/10.12816/0027366

Nelson, J. (2016). Using Conceptual Depth Criteria: Addressing the Challenge of Reaching Saturation in Qualitative Research. Qualitative Research, 17, 554-570. https://doi.org/10.1177/1468794116679873

Nemeckova, I. (2017). The Role of Benefits in Employee Motivation and Retention in the Financial Sector of the Czech Republic. Economic Research-Ekonomska Istraživanja, 30, 694-704. https://doi.org/10.1080/1331677X.2017.1314827

Nica, E. (2016). Employee Voluntary Turnover as a Negative Indicator of Organizational Effectiveness. Psych Sociological Issues in Human Resource Management, 4, 220-226.

Northouse, P. G. (2016). Leadership: Theory and Practice (7th ed.). Thousand Oaks, CA: Sage

Novianty, R. R., \& Evita, S. N. (2018). Financial Incentives: The Impact on Employee Motivation. Academy of Strategic Management Journal, 17, 1-8.

http://www.search.proquest.com

Ocen, E., Francis, K., \& Angundaru, G. (2017). The Role of Training in Building Employee Commitment: The Mediating Effect of Job Satisfaction. European Journal of Training and Development, 41, 742-757. https://doi.org/10.1108/EJTD-11-2016-0084

Ozer, E., J., \& Douglas, L. (2016). The Impact of Participatory Research on Urban Teens: An Experimental Evaluation. American Journal of Community Psychology, 51, 66-75. https://doi.org/10.1007/s10464-012-9546-2

Park, S., Hye-Seung, T., Kang, \& Eun-Jee, K. (2018). The Role of Supervisor Support on Employees' Training and Job Performance: An Empirical Study. European Journal of Training and Development, 42, 57-74. https://doi.org/10.1108/EJTD-06-2017-0054

Parker, L. D., \& Northcott, D. (2016). Qualitative Generalizing in Accounting Research: Concepts and Strategies. Accounting, Auditing, \& Accountability Journal, 29, 1100-1131. https://doi.org/10.1108/AAAJ-04-2015-2026

Porter, T. H., Riesenmy, K. D., \& Fields, D. (2016). Work Environment and Employee Motivation to Lead. American Journal of Business, 31, 66-84.

https://doi.org/10.1108/AJB-05-2015-0017

Porter, T. H., Riesenmy, K. D., \& Fields, D. (2016). Work Environment and Employee 
Motivation to Lead. American Journal of Business, 31, 66-84. https://doi.org/10.1108/AJB-05-2015-0017

Roulston, K. (2016). Issues Involved in Methodological Analyses of Research Interviews. Qualitative Research Journal, 16, 68-79. https://doi.org/10.1108/QRJ-02-2015-0015

Rozman, M., Treven, S., \& Čančer, V. (2017). Motivation and Satisfaction of Employees in the Workplace. Business Systems Research, 8, 14-25. https://doi.org/10.1515/bsrj-2017-0013

Sudiardhita, K. I. R., Mukhtar, S., Hartono, B., Herlitah, Sariwulan, T., \& Nikensari, S. I. (2018). Effect of Compensation, Motivation of Employee and Work Satisfaction to Employee Performance PT. BANK XYZ (PERSERO) TBK. Academy of Strategic Management Journal, 17, 1-14. http://www.abacademies.org

Sutanto, E. M., \& Kurniawan, M. (2017). The Impact of Recruitment, Employee Retention and Labor Relations to Employee Performance on Batik Industry in Solo City, Indonesia. International Journal of Business and Society, 17, 375-390. https://doi.org/10.33736/ijbs.531.2016

Thanyawatpornkul, R., Siengthai, S., \& Johri, L. M. (2016). Employee's Perspective towards Strategy Execution in Facility Management in Thailand. Facilities, 34, 682-702. https://doi.org/10.1108/F-09-2014-0071

The Bureau of Labor Statistics, U.S. Department of Labor (2015). Annual Employee Retailing Voluntary Turnover Rates. https://www.bls.gov/opub/mlr/2015/home.htm

Thomas, J., Silverman, S., \& Nelson, J. (2015). Research Methods in Physical Activity(7th ed.). Champaign, IL: Human Kinetics.

U.S. Census Bureau (2016). Geography Area Series: County Business Partners by Employment Seize Class: 2014 Partners. https://books.google.com/books?hl=en\&lr=\&id=cd4TJN4lnI4C\&oi=fnd

U.S. Small Business Administration (SBA) (2016). Frequent Asked Questions. http://www.sba.gov

Ugwu, L. I., Enwereuzor, I. K., \& Orji, E. U. (2016). Is Trust in Leadership a Mediator between Transformational Leadership and In-Role Performance among Small-Scale Factory Workers? Review of Managerial Science, 10, 629-648.

https://doi.org/10.1007/s11846-015-0170-z

Valaei, N., \& Jiroudi, S. (2016). Job Satisfaction and Job Performance in the Media Industry. Asia Pacific Journal of Marketing and Logistics, 28, 984-1014.

https://doi.org/10.1108/APJML-10-2015-0160

Vlacsekova, D., \& Mura, L. (2017). Effect of Motivational Tools on Employee Satisfaction in Small and Medium Enterprises. Oeconomia Copernicana, 8, 111-130. https://doi.org/10.24136/oc.v8i1.8

Webster, A., Bowron, C., Matthew-Maich, N., \& Patterson, P. (2016). The Effect of Nursing Staff on Student Learning in the Clinical Setting. Nursing Standard, 30, 40-47. https://doi.org/10.7748/ns.30.40.40.s44

Wnuk, M. (2017). Organizational Conditioning of Job Satisfaction. A Model of Job Satisfaction. Contemporary Economics, 11, 31-44. https://doi.org/10.5709/ce.1897-9254.227

Wong, W. P. M., Tee, N. E., \& Chin, C. H. (2018). Transformational Leadership, Motivation, and Organizational Commitment towards Corporate Social Responsibility in Banking Service Industry, Sarawak. Global Business and Management Research, 10, 58-70. http://www.researchgate.net

Yin. R. K. (2016). Case Study Research: Design and Methods (6th ed.). Thousand Oaks, 
CA: Sage

Yoke-Mui, L., Ahmad, Y., \& Nabavi, F. (2016). Causes of High Variance in Building Conservation Tenders in Malaysia. Structural Survey, 34, 98-116. https://doi.org/10.1108/SS-04-2015-0023

Zareen, M., Razzaq, K., \& Mujtaba, B. G. (2015). Impact of Transactional, Transformational and Laissez-Faire Leadership Styles in Motivation. A Quantitative Study of Banking Employees in Pakistan. Public Organizational Review, 15, 531-549.

https://doi.org/10.1007/s11115-014-0287-6

Zhang, J., Ahammad, M. F., Tarba, S., Cooper, C. L., Glaister, K. W., \& Wang, J. (2015). The Effect of Leadership Style on Talent Retention during Merger and Acquisition Integration: Evidence from China. International Journal of Human Resource Management, 26, 1021-1050. https://doi.org/10.1080/09585192.2014.908316 